2015 với các biến chứng viêm màng não và chảy máu ổ mổ và một số trường hợp tử vong. Các biến chứng khác cũng được ghi nhận nhưng với tần suất ít: rối loạn điện giải, rò dịch não tuỷ, chảy máu sau mổ, nhiễm trùng vết mổ, suy hô hấp.

Kết quả phầu thuật. Trong nghiên cứu này chúng tôi ghi nhân thấy $83 \%$ số bệnh nhân sau mổ có kết quả ổn định thuộc nhóm GOS độ 4, độ 5. Có 5 bệnh nhân ra viện ở GOS độ 3 chiếm 9,46\% gồm những bệnh nhân sau mổ bị biến chứng suy hô hấp, viêm màng não. 7,54\% số bệnh nhân sau mổ diễn biến nặng, đã được hồi sức tích cực nhưng tình trạng không cải thiện, gia đình xin bệnh nhân về.

\section{KẾT LUÂN}

Qua nghiên cứu 53 trường hợp phẫu thuật $\mathrm{u}$ nguyên bào tuỷ tại bệnh viện Việt Đức, chúng tôi thây kết quả $83 \%$ bệnh nhẩn ra viện trong nhóm ổn định (GOS độ 4, 5); 9,46\% ra viện GOS độ 3; $7,54 \%$ ra viện với diễn biến nặng sau mổ.

Các biến chứng sau mổ chúng tôi thu nhận được qua nghiên cứu gồm có chảy máu ngoài màng cứng, viêm màng não, suy hô hấp, rối loạn điện giải, rò dịch não tuỷ, nhiễm trùng vết mổ và đã được xử trí kịp thời và chính xác.

\section{TÀI LIÊU THAM KHẢO}

1. Tuyển BQ. Bệnh học thân kinh, sau đại học. Bệnh học thần kinh, sau đại học Nhà xuất bản quân đội nhân dân. 2003:207-224.

2. Millard NE, De Braganca KC. Medulloblastoma. Journal of Child Neurology. 2016;31(12):1341-1353.

3. Bavle A, Parsons DW. From One to Many: Further Refinement of Medulloblastoma Subtypes Offers Promise for Personalized Therapy. Cancer Cell. Jun 12 2017;31(6):727-729.

4. Poussaint TY, Rodriguez D. Advanced neuroimaging of pediatric brain tumors: MR diffusion, MR perfusion, and MR spectroscopy. Neuroimaging Clin N Am. Feb 2006;16(1):169-92, ix. doi:10.1016/j.nic.2005.11.005

5. JL H. Adult cerebellar medulloblastomas: the pathological, radiographic, and clinical disease spectrum. JNeurosurg. 1989; Vol 70:536-544.

6. Atalar B, Ozsahin M, Call J, et al. Treatment outcome and prognostic factors for adult patients with medulloblastoma: The Rare Cancer Network (RCN) experience. Radiother Oncol. Apr 2018;127(1):96-102.

doi:10.1016/j.radonc.2017.12.028

7. Haque $\mathbf{W}$, Verma $\mathbf{V}$, Brian Butler $E$, Teh BS. Prognostic role of chemotherapy, radiotherapy dose, and extent of surgical resection in adult medulloblastoma. Journal of Clinical Neuroscience. 2020;76:154-160. doi:10.1016/j.jocn.2020.04.002

8. Lee ST, Lui TN, Chang CN, Cheng WC. Early postoperative seizures after posterior fossa surgery. J Neurosurg. Oct 1990;73(4):541-4. doi:10.3171 / jns.1990.73.4.0541

9. Rath GP, Bithal PK, Chaturvedi A, Dash HH. Complications related to positioning in posterior fossa craniectomy. J Clin Neurosci. Jun 2007;14(6):520-5. doi:10.1016/j.jocn.2006.02.010

\title{
NGHIÊN CỨU ĐẶC ĐIỂM LÂM SÀNG VÀ KẾT QUẢ ĐIỀU TRI Ở BÊNNH NHÂN NHỒI MÁU NÃO Có RUNG NHĨ
}

\section{TÓM TẮT}

Đặt vấn đê: Trên thế giới, đột quỵ não là nguyên nhân gây tử vong thứ ba sau bệnh tim thiếu máu cục bộ và ung thư. Tại Việt Nam, ước tính hàng năm có khoảng 200.000 người bi đột quy. Theo đánh giá của Tổ chức $Y$ tế Thế giới (WHO, 2015), đột quy là nguyên nhân chính gây tử vong ở Việt Nam $(21,7 \%)$ với số lương bênh nhân tử vong hàng năm là 150.000 (Health Grove, 2013). Rung nhĩ là rối loạn nhịp tim kéo dài thường gă̆p nhất làm tăng tỷ lệ mắc bệnh, tử vong và gánh nặng kinh tế xã hội ở bệnh nhân đột quy. Tại Việt Nam, hiện chưa có nhiều nghiên cứu

\footnotetext{
${ }^{1}$ Trường Đại học Y Hà Nội

${ }^{2}$ Bênh viên Bach Mai

Chịu trách nhiệm chính: Võ Hồng Khôi

Email: drvohongkhoi@yahoo.com.vn

Ngày nhận bài: 22.10.2021

Ngày phản biên khoa họ: 20.12 .2021

Ngày duyệt bài: 30.12.2021
}

\section{Võ Hồng Khôi ${ }^{1,2}$, Lê Thị Nga ${ }^{1}$}

đánh giá về đăc điểm lâm sàng và kết quả điều tri ở bệnh nhân nhồi máu não có rung nhĩ. Muc tiêu: Nhận xét đắc điểm lâm sàng và kết quả điều trị ở bệnh nhân nhồi máu não có rung nhĩ. Đối tượng và phương pháp: Nghiên cứu mô tả tiến cứu 55 bệnh nhân nhồi máu não có rung nhĩ điều trị nội trú tại Trung tâm Thần kinh, Bênh viện Bạch Mai từ tháng 5 năm 2019 đến tháng 7 năm 2020. Kết quả: Nhồi máu não ở bệnh nhân rung nhĩ có triệu chứng lâm sàng trong thời kỳ toàn phát cũng tương tự như nhồi máu não ỡ các bệnh nhân khác, triệu chứng lâm sàng hay gặp nhất là liệt nửa người và rổi loạn ngôn ngữ (chiếm lần lượt $85,5 \%$ và $63,6 \%$ ). Đa số bệnh nhân có mức độ hồi phục lâm sàng kém (điểm mRS tại thời điểm xuất viện $\geq 3$ chiếm $65,5 \%$ ).

Tư khóa: nhồi máu não, rung nhĩ, triệu chứng lâm sàng, kết quả điều trị.

\section{SUMMARY \\ CLINICAL FEATURES AND OUTCOME IN ISCHEMIC STROKE PATIENTS WITH}




\section{ATRIAL FIBRILLATION}

Background: Stroke is the third most common cause of death worldwide after focal ischemic heart disease and cancer. In general stroke patients, ischemic type accounts for $85 \%$. Stroke patients due to cardioembolic etiology tend to have worse pronosis for recovery. Atrial fibrillation is the most common cardiac arrhythmia. The most serious common complication of atrial fibrillation is arterial thromboembolism; the most clinically evident thromboembolic event is ischemic stroke. In Vietnam, there have not been any studies on clinical features and outcome of ischemic stroke in patients with atrial fibrillation. Objectives: to describe clinical features and outcome in ischemic stroke patients with atrial fibrillation. Subjects and methods: A prospective, descripive study . Result: clinical symptoms of the fulminant period in stroke patients due to atrial fibrilation are similar to other causes. Most patients have poor clinical recovery from treatment.

Key words: ischemic stroke, atrial fibrillation, clinical features, outcomes.

\section{I. ĐĂT VẤN ĐỀ}

Trên thế giới, đột quy là nguyên nhân gây tử vong thứ ba sau bềnh lý tim mạch và ung thư, là nguyên nhân phổ biến nhất gây tàn phế vĩnh viền ở các nước công nghiệp hóa. Trong các thể đột quy, nhồi máu não chiếm $85 \%$, trong đó nguyên nhân thuyên tắc mạch do huyết khối từ tim thường gây ra hậu quả nặng nề hơn cả. Rung nhĩ là rối loạn nhịp tim thường gặp nhất với biến chứng là huyết khối động mạch mà biểu hiện thường gặp trên lâm sàng là nhồi máu não [1], [2]. Tại Việt Nam chưa có nhiêu nghiên cứu về đặc điểm lâm sàng và kết quả điều trị ở bệnh nhân nhồi máu não có rung nhĩ. Vì vậy, chúng tôi tiến hành nghiên cứu đề tài: "Nghiên cứu đăc điểm lâm sàng và kết quả điều trị ở bệnh nhân nhồi máu não có rung nhĩ".

II. ĐỐI TƯỢNG VÀ PHƯƠNG PHÁP NGHIÊN CỨU

Đối tượng nghiên cứu. Gồm 55 bệnh nhân được chẩn đoán nhồi máu não có rung nhĩ điều trị nội trú tại Trung tâm Thần kinh, Bệnh viện Bạch Mai từ tháng 5/2019 đến tháng 7/2020.

Tiêu chuẩn lựa chọn. Chọn tất cả bệnh nhân nhồi máu não có rung nhĩ.

- Tiêu chuẩn nhồi máu não: Lâm sàng: Đáp ứng tiêu chuẩn chẩn đoán tai biến mach máu não của Tổ chức y tế thế giới 1989. Chẩn đoán hình ảnh: Chụp cộng hưởng từ sọ não có hình ảnh tổn thương tăng tín hiệu trên T2W và FLAIR, hạn chế khuếch tán trên DWI.

- Tiêu chuẩn chẩn đoán rung nhĩ: Có ít nhất 1 điện tâm đồ trong lúc nằm viện có hình ảnh rung nhĩ, không phân biệt loại rung nhĩ.

Tiêu chuẩn loại trừ: Bệnh nhân nhồi máu não do huyết khối tĩnh mạch não, có các khiếm khuyết chức năng nặng trước khởi phát bệnh, có các bệnh nặng kèm theo ảnh hưởng đến kết cục, bệnh nhân và người nhà không đồng ý tham gia nghiên cứu.

Phương pháp nghiên cứu: Mô tả tiến cứu.

Phương pháp thống kê và xử lí số liệu: Theo chương trình SPSS 20.0

\section{KẾT QUẢ NGHIÊN CỨU}

1.Đặc điểm chung của đôii tượng nghiên cứu 1.1. Giới tính

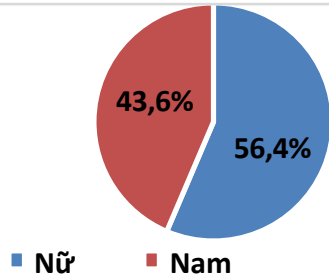

Biểu đồ 1. Phân bố bệnh nhân theo giới tính

Nhận xét: Trong nghiên cứu của chúng tôi bệnh nhân nữ nhiều hơn nam với tỷ lệ nữ/nam là 1,27 .

1.2.Tuổi

Bảng 1. Phân bố bênh nhân theo tuổi

\begin{tabular}{|c|c|c|}
\hline Nhóm tuối & Số bệnh nhân & Tỷ lệ\% \\
\hline$<65$ & 12 & 21,8 \\
\hline $65-74$ & 15 & 27,3 \\
\hline$\geq 75$ & 28 & 50,9 \\
\hline Tống & 55 & 100 \\
\hline$M \pm S D$ & \multicolumn{2}{|c|}{$72,64 \pm 11,91$} \\
\hline
\end{tabular}

Nhận xét: độ tuối trung bình của bệnh nhân là $72,64 \pm 11,91$. Trong đó, đa số bềnh nhân nằm trong nhóm $\geq 75$ tuổi ( 28 bệnh nhẩn).

2. Đặc điểm lâm sàng thân kinh

Bảng 2. Tỷ lệ các dấu hiệu lâm sàng chính

\begin{tabular}{|c|c|c|}
\hline Đặc điểm lâm sàng & $\begin{array}{c}\text { Số lượng } \\
\text { bệnh nhânn }\end{array}$ & $\begin{array}{c}\text { Tỷ lệ } \\
\text { \%ộ }\end{array}$ \\
\hline Rối loạn ý thức & 28 & 50,9 \\
\hline Đau đâuu & 20 & 36,4 \\
\hline Chóng mặt & 10 & 18,2 \\
\hline Liệt nửa người & 47 & 85,5 \\
\hline Rối loạn cảm giác & 14 & 25,5 \\
\hline Rối loạn cơ tròn & 18 & 32,7 \\
\hline Rối loạn nuốt & 31 & 56,4 \\
\hline Rối loạn ngôn ngữ & 35 & 63,6 \\
\hline
\end{tabular}

Nhận xét: chứng lâm sàng thường gặp nhất là liệt nửa người và rối loạn ngôn ngữ, lần lượt chiếm $85,5 \%$ và $63,6 \%$. Triệu chứng ít gặp nhất là chóng mă̆t, chỉ có $18,2 \%$ bệnh nhân biểu hiện dấu hiệu này.

Bảng 3: Phân bố bệnh nhân theo thang điểm NIHSS 


\begin{tabular}{|c|c|c|}
\hline Điếm NIHSS & Số bệnh nhân & Tỷ lệ\% \\
\hline$<\mathbf{6}$ & 16 & 29,1 \\
\hline $\mathbf{6 - 1 5}$ & 28 & 50,9 \\
\hline$>\mathbf{1 5}$ & 11 & 20 \\
\hline Tống & 55 & 100 \\
\hline
\end{tabular}

Nhận xét: bệnh nhân vào viện có điểm NIHSS chủ yếu nằm trong khoảng từ 6-15, chiếm $50,9 \%$.

\section{Kết quả điều trị}

Bảng 4. Phân bố bệh nhân theo điểm mRS tại thởi điểm 1 tháng sau xuất viện

\begin{tabular}{|c|c|c|c|c|c|c|c|c|}
\hline \multirow{2}{*}{ Điểm mRS } & \multicolumn{3}{|c|}{ Hồi phục tốt } & \multicolumn{3}{c|}{ Hồi phục kém } & \\
\cline { 2 - 9 } & 0 & 1 & 2 & 3 & 4 & 5 & 6 \\
\hline Số bệnh nhân & 6 & 8 & 5 & 20 & 6 & 1 & 9 \\
\hline Tỷ lệ\% & 10,9 & 14,5 & 9,1 & 36,4 & 10,9 & 1,8 & 16,4 & \\
\hline Tổng số & \multicolumn{3}{|c|}{$\mathbf{1 9}(\mathbf{3 4 , 5 \% )}$} & \multicolumn{3}{|c|}{$\mathbf{3 6}(\mathbf{6 5 , 5 \% )}$} \\
\hline
\end{tabular}

Nhận xét: Tại thời điểm 1 tháng sau xuất viện: số bệnh nhân hôi phục lâm sàng tốt là 19 (chiếm 34,5\%), số bệnh nhân hồi phục lâm sàng kém là 36 (chiếm 65,5\%). Có thể thấy số lượng bệnh nhân phục hồi kém nhiều hơn hẳn số bệnh nhân hồi phục tốt có ý nghĩa thống kê với $p=0,03(P<0,05)$.

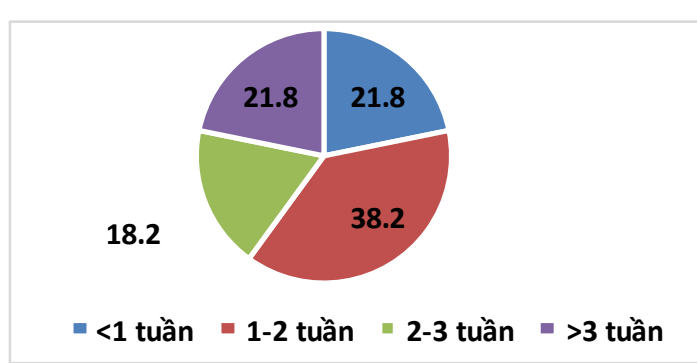

Biểu đồ 2. Thời gian điều trị

Nhận xét: Đa số bệnh nhân có thời gian nằm viện tữ $1-2$ tuần, chiếm tỷ lệ $38,2 \%$.

\section{BÀN LUẬN}

Trong nghiên cứu của chúng tôi, tỷ lệ bệnh nhân nữ nhiều hơn nam với tỷ lệ nữ:nam là $1,27: 1$. Kết quả này phù hợp với nghiên cứu của Đỗ Minh Chi, nữ chiếm ưu thế hơn nam $(53,4 \%)$ [3], nghiên cứu của Kanikabongbunkiat về tiên lượng tử vong lại bệnh viện ở bệnh nhân rung nhĩ có nhồi máu não, cho kết quả bệnh nhân nữ chiếm tỉ lệ nhiều hớn với $58,1 \%$ [4]. Khác với nghiên cứu của Lê Thị Thúy Hồng về đặc điểm lâm sàng, chụp cắt lớp vi tính và các yếu tố tiên lượng của bệnh nhân nhồi máu não có bệnh lý tim mạch, kết quả nam gặp nhiều hơn nữ với tỉ lệ nam/nữ là 1,6/1 [5]

Độ tuổi trung bình của bệnh nhân là 72,6 tuổi. Đa số bệnh nhân nằm trong nhóm tuổi trên 75 , chiếm 50,8\%. Tuổi thấp nhất là 34 tuổi, cao nhất là 92 tuổi. Kết quả này tương tự với nghiên cứu của của Kanikakongbunkiat cho thấy độ tuổi hay gặp của bệnh nhân nhồi máu não kèm rung nhĩ là 60 - 79 tuổi[4]. Tuy nhiên kết quả này cao hơn so với nghiên cứu của Lê Thị Thúy Hồng những bệnh nhân nhồi máu não có bệnh lý tim mạch chủ yếu có độ tuổi trên 50 tuổi, trong đó tỉ lệ hay gặp chủ yếu rơi vào nhóm 50 - 70 tuổi [5]

Trong nghiên cứu của chúng tôi, triệu chứng lâm sàng hay gặp nhất là liệt nửa người và rối loạn ngôn ngữ. Kết quả này tướng tự với nghiên cứu của William Akanska và công sự, số bênh nhân liệt nửa người chiếm $69 \%$, số bệnh nhân có rối loạn ngôn ngữ chiếm $67 \%$ [6]. Trong nghiên cứu của Lê Thị Thúy Hồng và Lê Văn Thính về đặc điểm lâm sàng, chụp cắt lớp vi tính và các yếu tố tiên lượng của bệnh nhân nhồi máu não có bệnh lý tim mạch, triệu chứng liệt nửa người 89,7\%, rối loạn ngôn ngữ chiếm 40,7\% [5].

Ở nghiên cứu của chúng tôi, tại thời điểm xuất viện, đa số bệnh nhân có độ hiồi phục lâm sàng kém (điểm $m R S \geq 3$ chiếm $71 \%$ ). Kết quả này phù hợp với nghiên cứu của Arauz và cộng sự, với mức độ phục hồi kém chiếm 71,4\% [8]. Tại thời điểm 1 tháng sau xuất viện, số bệnh nhân có điểm $m R S \geq 3$ vẫn chiếm tỷ lệ cao hơn số bệnh nhân có điểm mRS < 3 (chiếm $65,5 \%$ và $34,5 \%)$, sự khác biệt có ý nghĩa thống kê với $\mathrm{p}=0,03$, phù hợp với nghiên cứu của Đố Minh Chi và công sự [3]. Một nghiên cứu khác của Gole tại Ẩn độ trên 246 bệnh nhân bị nhồi máu não cấp cho kết quả, tỉ lệ bệnh nhân có mức độ hồi phục kèm $m R S \geq 3$ khi ra viện chiếm $62,6 \%$ [9].

Trong nghiên cứu của chúng tôi, đa số bênh nhân có thời gian nằm viện từ một đến hai tuần, chiếm $38 \%$. Kết quả này tương tự với nghiên cứu của Lê Thị Thúy Hồng và Lê Văn Thính, thời gian điều trị của nhóm bệnh nhân nhồi máu não có bệnh lý tim mạch chủ yếu là 2 tuần [5]. Một nghiển cứu của Santos và cộng sự trong 15 năm trên hơn hai trăm nghìn bệnh nhân nhồi máu não cho thấy thời gian nằm viện trung bình của nhóm nhồi máu não kèm rung nhĩ là 9 ngày.

\section{KẾT LUÂN}

-Bệnh nhân nhồi máu não có rung nhĩ thường gặp ở nữ nhiều hơn nam với độ tuổi trung bình là 72,6 tuổi.

- Nhồi máu não ở bệnh nhân có rung nhĩ triệu 
chứng lâm sàng trong thời kỳ toàn phát thường gặp là liệt nửa người và rối loạn ngôn ngữ.

- Hầu hết bệnh nhân có mức độ hồi phục kém sau điều trị với thời gian nằm viện trung bình là từ 1 đến 2 tuần.

\section{TÀI LIÊU THAM KHẢO}

1. GBD 2016 Stroke Collaborators (2019). Global, regional, and national burden of stroke, 1990-2016: a systematic analysis for the Global Burden of Disease Study 2016. Lancet Neurol, 18(5), 439-458.

2. 2020 ESC Guidelines for the diagnosis and management of atrial fibrillation developed in collaboration with the European Association of Cardio-Thoracic Surgery (EACTS) | European Heart Journal | Oxford Academic. <https:// academic.oup.com/eurheartj/advance-article/doi/ 10.1093/eurheartj/ ehaa612/5899003>, accessed: 18/10/2020.

3. Đố Minh Chi C.P.P. (2014). Nghiên cứu các yếu tố tiên lượng trên bệnh nhân nhồi máu não có rung nhĩ.

4. Kongbunkiat K., Kasemsap N., Travanichakul
S. và cộng sự. (2015). Hospital mortality from atrial fibrillation associated with ischemic stroke: a national data report. Int J Neurosci, 125(12), 924-928.

5. Lê Thi Thúy Hồng L.V.T. (2015). Đăc điểm lâm sàng, chụp cắt lớp vi tính và các yếu tố tiên lượng của bênh nhân nhồi máu não có bênh lý tim mạch.

6. Akanksha W.G., Paramdeep K., Gagandeep S. và cộng sư. (2017). Clinical Features, Risk Factors, and Short-term Outcome of Ischemic Stroke, in Patients with Atrial Fibrillation: Data from a Population-based Study. Ann Indian Acad Neurol, 20(3), 289-293.

7. Chu Bá Chung (2017). Nghiên cứu các yễu tố tiên lượng tử vong trên bệnh nhân nhồi máu não trong bốn tuân đâu. .

8. Arauz A., Ruiz-Navarro F., Barboza M.A. và cộng sự. (2017). Outcome, Recurrence and Mortality after Non-Valvular Atrial Fibrillation Stroke: Long-Term Follow-Up Study. J Vasc Interv Neurol, 9(6), 5-11.

9. Goel D., Gupta R., Keshri T. và công sứ. (2020). Prevalence of atrial fibrillation in acute ischemic stroke patients: A hospital-based study from India. Brain Circ, 6(1), 19-25.

\section{NHÂ̂N XÉT ĐĂC ĐIỂM LÂM SÀNG, CÂN LÂM SÀNG BỆNH NHÂN SỎI ỐNG MÂTT CHỦ CÓ TÚI THỪA TÁ TRÀNG VÀ KHÔNG Có TÚI THỪA TÁ TRÀNG \\ Nguyễn Công Long', Nguyễn Thị Dân²}

\section{TÓM TẮT}

Mục tiêu: Túi thừa quanh papilla (PAD) không phải ít gặp khi tiến hành nội soi mật tụy ngược dòng (ERCP), nhưng đặc điểm lâm sàng bệnh nhân sỏi mật có túi thừa ít đước nghiên cứu, do vây chúng tồi nghiên cứu đặc điểm lâm sàng bệnh nhẩn có sỏi mật chủ ở bênh nhân có túi thừa. Đối tượng và phương pháp: 60 bệnh nhân sỏi ống mật chư được tiến hành ERCP quan sát túi thừa quanh papilla từ tháng 7 năm 2019 đến tháng 9 năm 2020 được đưa vào nghiên cứu ghi nhận đặc điểm lâm sàng, xét nghiệm, mô tả đặc điểm và phẩn loại túi thừa. Kết quả: Tuổi trung bình bênh nhân, kích thước sỏi ống mât chủ ở bênh nhân có sự khác biệt giữa nhóm bệnh nhân sỏi ống mật chủ có hoặc không có túi thừa, và loại túi thừa hay gặp nhất là type II. Triêu chứng lâm sàng khá tương đồng giữa nhóm có túi thừa và không có túi thừa. Độ nặng viêm đường mât theo phân loai Tokyo thì ở nhóm có túi thửa PAD có biểu hiện nặng hơn nhóm không có túi thừa tuy nhiên khác biêt không có ý nghĩa thống kê. Kết luận: Nghiên cứu cho thấy túi thừa quanh papilla thường gặp ở người cao tuối và thường gây

1 Trung tâm tiêu hóa gan mật Bênh viện Bạch mai 2Bệnh huyện Văn Giang, Hưng Yên

Chịu trách nhiệm chính: Nguyển Công Long

Email: nguyenconglongbvbm@gmail.com

Ngày nhân bài: 20.10.2021

Ngày phản biên khoa hoc: 20.12.2021

Ngày duyệt bài: 28.12.2021 nhiễm trùng đường mật nặng hơn ở bệnh nhân có sỏi ống mât chủ. thừa

Tư khóa: Viêm đường mật, sỏi ống mật chủ, túi

\section{SUMMARY \\ CHARACTERISTICS OF CLINICALLY IN \\ COMMON BILE DUCT STONE PATIENTS ARE ASSOCIATED WITH PERIAMPULLARY DUODENAL DIVERTICULAR}

Objective: Periampullary diverticula (PAD) are not uncommon findings during endoscopic retrograde cholangiopancreatography, but its clinical significance had not been established. To investigate the clinical characteristics associated with PAD and their relationships with the type and size of PAD in patients with common bile duct (CBD) stones was aimed. Subjects and methods: Sixty patients undergoing endoscopic retrograde cholangiopancreatography between July 2019 and September 2020 were consecutively enrolled, and their demographics, laboratory data, and CBD stone-related characteristics according to PAD type and PAD size were analyzed. Results: Mean age, mean size of $C B D$ stones in patients with CBD stones differed in patients with CBD stones according to the presence or absence of PAD. The commonly presence of PAD was PAD type II, cholangitis symptoms were the similar in two groups with PAD or without PAD. The severity of cholangitis according to Tokyo classification was higher in the group with PAD than in the group without PAD, but 